\title{
Linking Advertising, Materialism, and Life Satisfaction
}

\author{
M. Joseph Sirgy • Eda Gurel-Atay $\cdot$ Dave Webb $\cdot$ Muris Cicic • \\ Melika Husic • Ahmet Ekici • Andreas Herrmann • Ibrahim Hegazy • \\ Dong-Jin Lee $\cdot$ J. S. Johar
}

Accepted: 6 March 2011 / Published online: 13 March 2011

(C) Springer Science+Business Media B.V. 2011

\begin{abstract}
This paper develops theory related to advertising, materialism, and life satisfaction by formally testing explanations related to the antecedents and consequences of materialism. Survey data were collected from seven major cities each in a different country (Australia, Bosnia/Herzegovina, Germany, Egypt, Korea, Turkey, and the USA) using a probability sample (cluster sampling method involving income stratification). The results showed that the extent to which advertising is perceived to be materialistic contributes to materialism. Materialism, in turn, leads to the frequent use of various standards of comparison in making judgments about standard of living. As judgments about standard of living increase, standard of living is evaluated more negatively. In turn, negative selfevaluations contribute significantly to dissatisfaction with life.
\end{abstract}

\author{
M. J. Sirgy $(\bowtie)$ \\ Virginia Polytechnic Institute and State University, Blacksburg, VA, USA \\ e-mail: sirgy@vt.edu \\ E. Gurel-Atay \\ University of Oregon, Eugene, OR, USA \\ e-mail: egurelat@uoregon.edu \\ D. Webb \\ University of Western Australia, Perth, WA, Australia \\ e-mail: dave.webb@uwa.edu.au \\ M. Cicic - M. Husic \\ University of Sarajevo, Sarajevo, Bosnia-Herzegovina \\ e-mail: murris.cicic@efsa.unsa.ba \\ M. Husic \\ e-mail: melika.husic@efsa.unsa.ba
}

A. Ekici

Bilkent University, Ankara, Turkey

e-mail: ekici@bilkent.edu.tr 
Keywords Materialism - Television viewership · Materialistic advertising ·

Evaluation of standard of living · Life satisfaction

The critics of advertising have long criticized the advertising (as an institution) for propagating materialism (Schudson 1984; Zinkhan 1994). Advertising concentrates on what we have (material possessions), not what we are (being human). Campbell (1987) assumes that consumers are motivationally empty until injected by marketers with wants created by advertising. Some scholars believe that the argument denouncing "hedonism as consumerism" represents a gross simplification of complex issues. Marketing does not create or invent wants but merely surfaces them: materialism became part of the human condition long before the rise of the advertising institution (O'Shaughnessy and O'Shaughnessy 2002). The impact of television advertising on society has long been debated since television and television advertising were introduced in the 1940s. Industry, consumer groups, and government have long sought to gain some understanding concerning how television viewership, and more specifically television advertising, contributes to the quality of life in society (Hyman et al. 1994).

Much research has been conducted in this area (see literature review on materialism by Larsen et al. 1999). Nevertheless questions remain. For example, extant research has not answered the following research questions conclusively: How does television viewership influence life satisfaction? How does materialism affect life satisfaction? What is the relationship between the extent to which advertising is perceived to be materialistic and materialism itself? What is the role of overall standard of living in linking materialism with life satisfaction? Additionally, does the frequency with which evaluations of standard of living are made affect the link between materialism and life satisfaction? The current study is designed to address these research questions. Specifically, a survey research was conducted in seven major cities each in a different country (Australia, Bosnia/Herzegovina, Germany, Egypt, Korea, Turkey, and the USA) using a probability sample (cluster sampling method involving income stratification). The goal in this paper is to advance the theory related to the links of advertising, materialism, and life satisfaction by developing alternative conceptual models (based on the available body of research) and testing these models in attempt to address the aforementioned research questions.

\author{
A. Herrmann \\ St. Gallen University, St. Gallen, Switzerland \\ e-mail: andreas.herrmann@unisg.ch \\ I. Hegazy \\ American University in Cairo, Cairo, Egypt \\ e-mail: hegazy@aucegypt.edu \\ D.-J. Lee \\ Yonsei University, Seoul, Korea \\ e-mail: djlee81@yonsei.ac.kr
}




\section{Conceptual Development}

The literature related to the overarching link between television viewership and life satisfaction is reviewed first, and a general model that captures this relationship is articulated. Then, a specific hypothesis related to this relationship is developed to test. Next, the concept of materialism is injected in the discussion in an attempt to better understand the role of materialism in the relationship between television viewership and life satisfaction. In doing so, the discussion is broken down in terms of the relationship between materialism and life satisfaction and the relationship between materialism and television viewership. Accordingly, the literature is reviewed and alternative models that can be subjected to rigorous empirical testing are developed.

\subsection{Television Viewership and Life Satisfaction}

In a seminal study examining the relationship between television viewership and life satisfaction, Morgan (1984) found significant but low negative correlations between television viewership and perceived quality of life. Rahtz et al. (1988a) examined the relationship between television viewership and life satisfaction among the elderly and found that television viewership was correlated negatively and significantly with life satisfaction. Rahtz et al. (1988b) were able to replicate these findings. Building on this work, Rahtz et al. (1989) found that television orientation among the elderly tended to correlate significantly and negatively with overall morale. They also found significant and positive correlations between television orientation and concern about one's personal and financial well being. The combined results support the view that television viewership and life satisfaction are negatively linked, particularly among the elderly.

The negative relationship between television viewership and life satisfaction is captured in Fig. 1 and will be subjected to an empirical validation test in this study. Thus, the first goal in this study is to replicate the negative relationship between television viewership and life satisfaction. The Morgan and Rahtz et al. studies were limited to US respondents with the latter being furthermore limited to a US elderly population. This study will replicate their finding using a general adult sample not only from the US but also using samples from other developed and developing countries. It should be emphasized that the objective of using multi-country sample is not to make cross-country comparisons, but rather, simply to establish the robustness of findings. It is believed that this negative relationship between television viewership and life satisfaction is not likely to hold up under greater scrutiny mainly because of the mediating effects that will be described momentarily. In other words, a direct effect is not expected. Specifically, based on the preceding discussion it is hypothesized that television viewership is not a negative predictor of life satisfaction $(\mathrm{H} 1)$. Testing this hypothesis requires the control of mediating variables that will be described in the sections below.

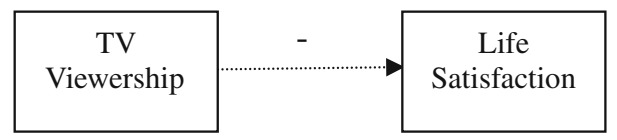

Fig. 1 The relationship (or lack thereof) between TV viewership and life satisfaction 
Fig. 2 The relationship between materialism and life satisfaction

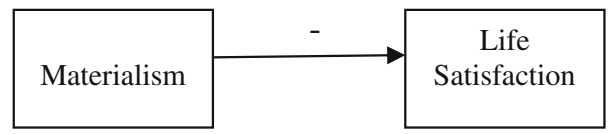

\subsection{Television Viewership, Materialism, and Life Satisfaction}

How do we account for the negative relationship between television viewership and life satisfaction? Much research has suggested that this relationship may be explained through materialism (e.g., Belk and Pollay 1985a, b; Buijzen and Valkenburg 2003; Fox and Philliber 1978; O’Shaughnessy and O'Shaughnessy 2002; Pine and Nash 2002; Pollay 1986; Richins 1987; Shrum et al. 2005; Sirgy et al. 1998a; Zinkhan 1994). To do so, the link between materialism and life satisfaction will be examined first and the relationship between materialism and television viewership will be examined next.

\subsubsection{Materialism and Life Satisfaction}

Belk (1984, p. 291), an eminent scholar in the field of materialism defines materialism as: "the importance a consumer attaches to worldly possessions." $\mathrm{He}$ continues: "At the highest levels of materialism, such possessions assume a central place in a person's life and are believed to provide the greatest source of satisfaction and dissatisfaction in life" (p. 291).

Materialistic people believe that the continued acquisition of possessions will lead to greater happiness and satisfaction in life, and that lack of possessions will lead to dissatisfaction in life. Ironically, much research has shown the opposite. In other words, dissatisfaction with life, not satisfaction, is the result of a materialistic orientation (e.g., Belk 1984, 1985; Chang and Arkin 2002; Dawson and Bamossy 1991; Burroughs and Rindfeisch 2002; Keng et al. 2000; La Barbera and Gurhan 1997; Richins 1987, 2004; Richins and Dawson 1992; Wright and Larsen 1993).

At least two explanations account for the negative relationship between materialism and life satisfaction: top-down theory of subjective well-being and bottom-up theory of subjective well-being. Quality-of-life researchers have consistently adopted these two theories to explain the determinants of life satisfaction (see Diener 1984 and Diener et al. 1999 for a review of the literature). The top-down theory of subjective well-being states that life satisfaction is influenced by personality or dispositional factors (e.g., self-esteem, alienation, optimism, pessimism, neuroticism). In contrast, the bottom-up theory of subjective well-being argues that life satisfaction is influenced by situational factors (e.g., satisfaction with standard of living, job, family, leisure, neighborhood, community).

In terms of the former, Belk (1985) suggested that materialistic people are usually possessive, non-generous, and envious. These are dispositional factors, reflecting a tendency to experience negative emotions. Thus, one can argue that the negative affect related to dispositional materialism spills over (top-down) to influence life satisfaction (i.e., materialism negatively influences life satisfaction. The explanation of the negative relationship between materialism and life satisfaction leads to the second model (see Fig. 2). Thus, it is hypothesized that materialism is negatively related to life satisfaction $(\mathrm{H} 2)$. The goal here is to replicate previous studies using a general adult sample not only from the US but also using samples from other developed and developing countries. Consequently, the intend here is to establish the robustness of the relationship. 


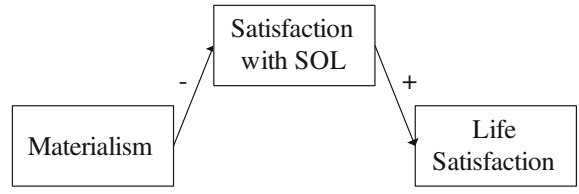

Model 3a

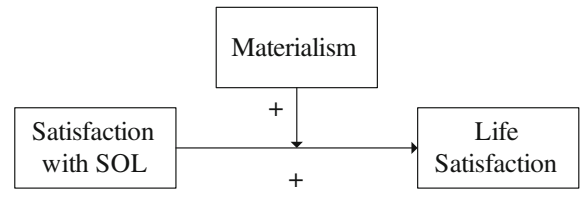

Model 3b

Fig. 3 Two alternative models representing the interrelationship among materialism, satisfaction with standard of living (SOL), and life satisfaction

In terms of the latter, bottom-up theory states that life satisfaction is greatly influenced by life domain evaluations. Specifically, positive and negative affect are invested in life domains capturing certain types of emotional experiences such as family life, leisure life, love life, work life, social life, spiritual life, and so on. One important life domain is material life (or standard of living assessed in material terms). The material life domain houses emotional reactions related to material possessions, household income, savings, investment, and other material resources related to personal wealth. Thus, life satisfaction/ dissatisfaction judgments are directly influenced by how one feels about important life domains such as material life. Sirgy et al. (1998a) demonstrated that the negative relationship between materialism and life satisfaction is mediated by evaluation of standard of living. Specifically, their study found that materialistic people are less satisfied with their material possessions and, in turn, less satisfied with life than non-materialistic people. This bottom-up explanation of the negative relationship between materialism and life satisfaction leads to the third model (see Model 3a in Fig. 3). Based on the preceding discussion it is hypothesized that materialism is a negative predictor of life satisfaction mediated by satisfaction with standard of living (SOL). Specifically, materialism is a negative predictor of satisfaction with SOL, and satisfaction with SOL is a positive predictor of life satisfaction (H3a).

Alternatively, one could also posit that the predictive effect of satisfaction with standard of living on life satisfaction is moderated by materialism. The extent of spillover of affect from the material domain to life satisfaction is subject to the saliency or relative importance of the material domain in relation to other life domains. Materialism can be construed as reflecting greater salience to material life compared to other life domains. In other words, materialistic people tend to regard their material life as very important compared to other life domains such as social life, leisure life, family life, spiritual life, etc. The literature in quality-of-life studies has documented much evidence concerning the salience of specific life domains in moderating the affect from these domains on life satisfaction (see Frisch 2006, 2008 for examples).

In the consumer behavior literature, evidence exists to suggest that materialism may in fact moderate the effect of satisfaction with standard of living on life satisfaction such that the effect is likely to be more pronounced for materialistic than non-materialistic people (Sirgy et al. 1998b). Consequently, the moderating effect of materialism on the relationship between satisfaction with standard of living and life satisfaction is presented as an alternative model for empirical testing (see Model 3b in Fig. 3). Based on the preceding discussion it is hypothesized that materialism moderates the effect of satisfaction with SOL on life satisfaction. Specifically, the strength of the relationship between satisfaction with SOL and life satisfaction is likely to be more evident for materialistic than non-materialistic people ( $\mathrm{H} 3 \mathrm{~b})$. 


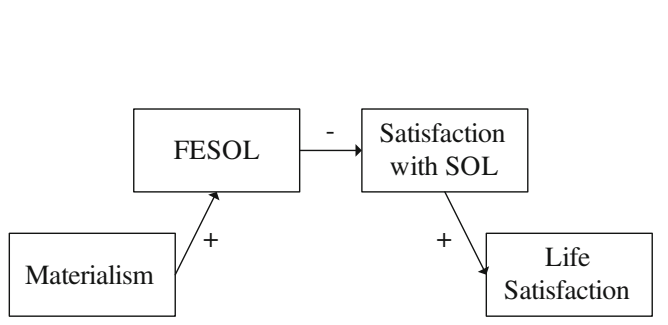

Model 4a

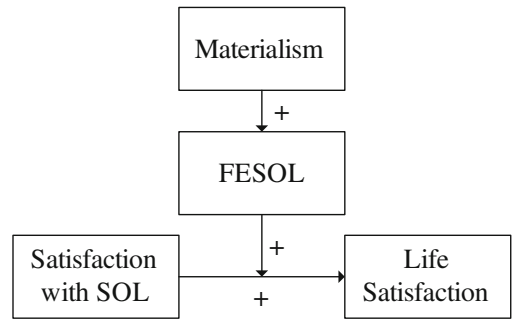

Model 4b

Fig. 4 Two alternative models representing the interrelationship among materialism, frequency of evaluation of SOL (FESOL), satisfaction with standard of living (SOL), and life satisfaction

Furthermore, Sirgy (1998) proposed that materialistic people have inflated expectations of their standard of living, whereas non-materialistic people have realistic expectations. He elaborated on various types of standards and how materialistic people (compared to nonmaterialistic people) use these expectations. He delineated six types of expectations: expectations based on (1) their ideal view of standard of living, (2) what they feel they deserve in terms of financial resources, (3) what they need to maintain a certain lifestyle, (4) what they have predicted all along in attaining a certain level of personal wealth, (5) how far they have progressed in relation to what they had in the past, and (6) how much personal wealth they were able to amass based on their ability (i.e., their educational background, inheritance, socio-economic status, etc.). Materialistic people tend to make more frequent evaluations of their standard of living using these six types of expectations. Thus, the more often standard of living is evaluated, the more it is for such evaluations to be negative. The negative affect generated from negative evaluation of standard of living spills over to judgments of life overall, making materialistic people feel dissatisfied with life. This extended version of the bottom-up explanation of the negative relationship between materialism and life satisfaction leads to two alternative models (models $4 \mathrm{a}$ and 4b) shown in Fig. 4.

That is, the more materialistic a person is, the more likely that this person will evaluate his or her standard of living with greater frequency, because the material life is very important to him or her. In other words, materialistic people are preoccupied with material life, which makes them evaluate their standard of living (SOL) a lot more than the nonmaterialistic people. Therefore, the greater the materialism the more often they evaluate their standard of living (positive relationship). People who frequently evaluate their standard of living are likely to arrive at negative evaluations more so than people who do not frequently evaluate their standard of living. Why? Perhaps this may be due to the fact that some of the standard of comparisons they may use are based on the type of standards that are likely to lead to negative evaluations. For example, a person is likely to evaluate his or her standard of living negatively if he or she were to use ideal expectations as the standard of comparison. An example of "ideal expectation" is "I want to be rich." Most people are likely to feel disappointed with their standard of living if they evaluate their current state of affairs against such standards. Therefore the hypothesized relationship between frequency of evaluations of standard of living and satisfaction with standard of living is negative in this instance. Finally, there is the positive relationship between satisfaction with standard of living and life satisfaction. The more a person feels satisfied with 
his or her standard of living the more he or she is likely to feel satisfied with his or her life at large, and vice versa.

In sum, it is hypothesized that materialism is a negative predictor of life satisfaction mediated by frequency of evaluation of SOL and satisfaction with SOL. Specifically, materialism is a positive predictor of frequency of evaluation of SOL, frequency of evaluation of SOL is a negative predictor of satisfaction with SOL, and satisfaction with SOL is a positive predictor of life satisfaction (H4a). Alternatively, materialism is a positive predictor of frequency of evaluation of SOL, and frequency of evaluation of SOL moderates the relationship between satisfaction with SOL and life satisfaction such that the higher the frequency of evaluation of SOL the stronger the effect of satisfaction with SOL on life satisfaction (H4b).

\subsubsection{Television Viewership and Materialism}

One of the most examined antecedents of materialism is television viewership (e.g., Fox and Philliber 1978; Goldberg and Gorn 1978; Greenberg and Brand 1993; O'Guinn and Shrum 1997; Potter 1991; Rahtz et al. 1989; Shrum et al. 2005; Sirgy et al. 1998a). For example, Richins (1987) was able to demonstrate a linkage between television viewership and materialism in a general adult sample. Specifically, the study revealed a significant relationship between television viewership and materialism; however, the relationship was present only for individuals who believed television commercial portrayals of consumers to be realistic. The cultivation hypothesis provides one explanation for the relationship between television viewership and materialism (see literature review on materialism by Larsen et al. 1999).

With respect to the cultivation hypothesis, media critics have long argued that people's construction of social reality is a direct function of media exposure and information acceptance of both program content and advertising (Caughey 1984; see Hawkins and Pingree 1981 for a review; Shrum 1999). More specifically, mass media studies related to television effects have demonstrated that heavy viewers of television have higher expectations of being crime victims than do light viewers (Gerbner et al. 1980a) and underestimate the number of older people in America more than light television viewers (Gerbner et al. 1980b). In both cases, the perception of heavy viewers is more discrepant from reality than the perception of light viewers. Heavy viewers seem to use television as a dominant source for cultivating beliefs that are, in fact, different from reality.

O'Guinn et al. (1986) proposed that the medium may be very much the message. People who become socialized predominantly through the mass media are likely to think and behave differently from those who experience the world about them more directly. Their basic premise is that the mass media emphasize different values than other acculturation sources. In a follow up, O'Guinn et al. (1989) suggested that over time, heavy television viewers will begin to develop perceptions of the world that are similar to what is shown on television-an effect called "main streaming." Pilot research with a student sample supported the contention that main streaming is indeed a consequence of heavy television viewing. A later study (Shrum et al. 1991) with 800 adult respondents supported the contention that heavy television viewing influences consumption perceptions and that heavy viewers' sense of reality is very similar to the reality portrayed on television.

Studies conducted in North America have been extended to other countries. Weiman (1984) found support for the contention that media messages affect images held about Americans by Israelis who heavily view Israeli television, a medium dominated by American television offerings. A study comparing Taiwanese residents of the United States 
with non-Taiwanese Americans found that the cultivation hypothesis was supported for all three groups (Lee 1989). Heavy television viewers were affected in that their distorted sense of consumption converged more with the world of television than with the real world.

Empirically speaking, many studies have supported the cultivation hypothesis (e.g., Belk and Pollay 1985a, b; Goldberg and Gorn 1978; Greenberg and Brand 1993; O'Guinn and Shrum 1997; Pollay 1986; Rahtz et al. 1989; Shrum et al. 2005; Shrum et al. 1998; Sirgy et al. 1998a; Zinkhan and Prenshaw 1994). For instance, Shrum et al. (2005) empirically demonstrated that television viewership contributes to materialism with heavy viewers paying more attention to messages related to societal affluence than light users. In comparison to light viewers, heavy viewers are exposed to what could be described as more materialistic advertising with greater recall of advertising related to affluence, status, and prestige. Also, research has shown that consumers use information from television to make inferences about the prevalence of affluence. Heavy viewers believe luxury products and services to be more commonplace than they actually are (O'Guinn and Shrum 1997; Shrum et al. 1998).

It is believed that the extent to which advertising is perceived to be materialistic might mediate the relationship between television viewership and materialism. In other words, television viewing might increase the extent to which advertising is perceived to be materialistic, which in turn, augments materialism. Therefore, perception of ads that link consumer goods and services with status and prestige is hypothesized to be a key factor influencing materialism (Moschis and Moore 1982; Buijzen and Valkenburg 2003; Pine and Nash 2002).

The cultivation hypothesis and the overall pattern of empirical findings suggest that heavy viewers may cultivate unrealistic beliefs about people and their surroundings. More particularly, such viewers are likely to believe most people are materially well off (affluent). That is, they may overestimate the material well-being of the average person. Overestimating the material well-being of the average person may occur as a reflection of exposure to television advertising that focuses on status and prestige goods. In other words, when television advertising emphasizes luxury goods and services (compared to necessity goods and services), the result is the cultivation of the belief that most people are affluent and financially well-off, and that the path to success in life is through the acquisition of material goods and the accumulation of personal wealth. Based on this discussion, we develop and test the following hypothesis (see Model 5a in Fig. 5): Television viewership is a positive predictor of perceived materialism in advertising (PMat), which in turn, is a positive predictor of materialism (H5a).

The preceding hypothesis reflects the mediation effect of PMat in advertising. However, one can also argue that the same construct moderates, instead of mediates, the relationship between television viewership and materialism (see the Model 5b in Fig. 5). In other words, the effect of television viewership on materialism is strengthened given high levels of PMat in advertising. The hypothesized moderation effect is consistent with the research by Shrum et al. (2005). Specifically, they were able to demonstrate that the process by which television influences materialism is different from the process by which it influences perceptions of societal affluence; that attention and elaboration for materialistic advertising messages moderate the predictive effect of television viewership on materialism. Thus, the alternative moderation can formally be stated: Television viewership is a positive predictor of materialism, moderated by PMat in advertising. Specifically, the predictive effect of television viewership on materialism is stronger for consumers whose perception of the extent of materialism in advertising is high rather than low (H5b). 

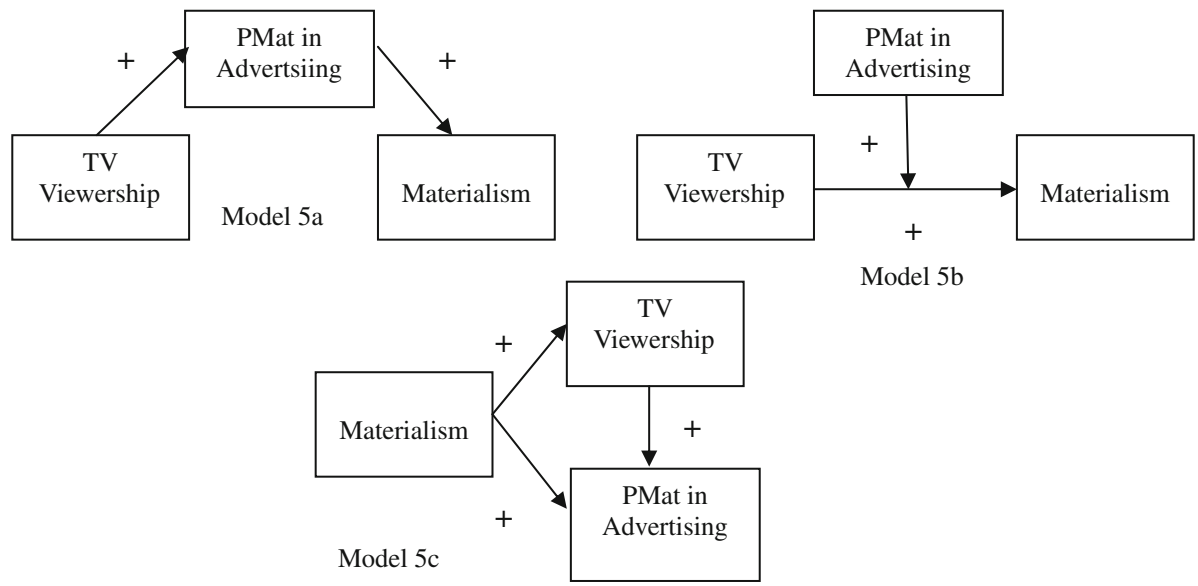

Model 5b

Fig. 5 Three alternative models representing the interrelationship among TV viewership, perceived materialism (PMat) in advertising, and materialism

Arguably, one can also develop yet another alternative model to explain the relationship among television viewership, PMat in advertising, and materialism. This model specifies that materialism is the cause, not the consequence, of television viewership. In other words, materialistic people are likely to view television more frequently than non-materialistic people. Why? Materialistic people may gravitate towards television because much of the television landscape is about the material world - television shows concentrate on the rich and famous; television news focus much on money, finance, and the economy; and television commercials are mostly related to shopping and material possessions. Therefore, it is materialism that induces people (at least in part) to television viewership, not the other way around. Also compared to non-materialistic people, materialistic consumers are likely to notice and recall more materialistic advertising than non-materialistic. Perhaps because materialistic people are preoccupied with materials possessions, making them more attentive to advertising of status and prestige goods and services. And of course, television viewership is likely to influence PMat in advertising; therefore, respondents may report higher levels of recall of materialistic television commercials. These relationships are captured in Model 5c in Fig. 5. Formally stated, the third alternative model leads to the following hypotheses: Materialism is a positive predictor of television viewership and PMat in advertising. Also, television viewership is a positive predictor of PMat in advertising. (H5c).

\section{Method}

\subsection{Sampling and Data Collection}

To test the various conceptual models shown in Figs. 1, 2, 3, 4, and 5, a consumer survey was conducted in a city in each of seven countries in 2007: Australia, Bosnia and Herzegovina, Germany, Egypt, Turkey, Korea, and the United States. The survey questionnaire was translated to local languages and then back-translated to English by bilingual speakers in each country. Thereafter, a stratified/cluster sampling technique was used to collect the 
Table 1 Descriptive statistics (Total sample size $=1,185$ )

\begin{tabular}{|c|c|c|c|c|c|c|c|}
\hline & Australia & $\begin{array}{l}\text { Bosnia and } \\
\text { Herzegovina }\end{array}$ & Germany & Egypt & Korea & Turkey & USA \\
\hline \multicolumn{8}{|l|}{ Gender } \\
\hline Men $(\%)$ & $57(44.5)$ & $120(39.9)$ & $58(39.7)$ & $54(36.2)$ & $31(20.9)$ & $72(48)$ & $78(47.9)$ \\
\hline Women $(\%)$ & $70(54.7)$ & $180(59.8)$ & $88(60.3)$ & $95(63.8)$ & $117(70.1)$ & $76(50.7)$ & $84(51.5)$ \\
\hline Missing (\%) & $1(.80)$ & $1(.30)$ & NA & NA & NA & $2(1.3)$ & $1(.60)$ \\
\hline \multicolumn{8}{|l|}{ Age } \\
\hline Range & $18-81$ & $18-84$ & $18-87$ & $18-65$ & $20-61$ & $18-67$ & $18-83$ \\
\hline Mean & 39.36 & 36.36 & 46.17 & 33.44 & 49.31 & 35.05 & 39.17 \\
\hline \multicolumn{8}{|l|}{ Income level } \\
\hline Low $(\%)$ & $31(24.2)$ & $101(33.6)$ & 49 (33.6) & 49 (32.9) & $49(33.1)$ & $50(33.3)$ & $61(37.4)$ \\
\hline Medium (\%) & $36(28.1)$ & $100(33.2)$ & $48(32.9)$ & $50(33.6)$ & $48(32.4)$ & $50(33.3)$ & $50(30.7)$ \\
\hline High (\%) & $61(47.7)$ & $100(33.2)$ & 49 (33.6) & $50(33.6)$ & $51(34.5)$ & $(33.3)$ & $52(31.9)$ \\
\hline \multicolumn{8}{|l|}{ Sample size } \\
\hline Original sample size & 128 & 301 & 146 & 149 & 148 & 150 & 163 \\
\hline Number of deleted cases & 21 & NA & NA & NA & 3 & 23 & NA \\
\hline Final sample size & 107 & 301 & 146 & 149 & 145 & 127 & 163 \\
\hline
\end{tabular}

data. Specifically, each city was divided into neighborhoods and these neighborhoods were categorized as being of high, medium, or low income. After selecting two sample neighborhoods from each category, a systematic-random sampling procedure was used to collect the survey data. Once a potential respondent agreed to complete the questionnaire, the researcher made arrangements to pick up the questionnaires 4-7 days later. One hundred twenty-eight, 301, 149, 146, 148, 150, and 163 completed questionnaires were collected in the aforementioned countries. Of the 1,185 respondents from these seven countries, approximately $40 \%$ were men and $60 \%$ were women. The age of respondents ranged from 18 to 87 with a mean of 39.37. Forty-seven cases were deleted from the analyses due to significant missing data. Following deletion, the percentage of missing data was less than five percent for each variable and those missing data were randomly distributed. Therefore, they were handled by using maximum likelihood estimation. Table 1 shows descriptive statistics for each country separately.

\subsection{Measures}

\subsubsection{Television Viewership}

Three items were adapted from Churchill and Moschis (1979) to measure television viewership. Two items identified how many hours participants spent watching television in a day during the weekdays and weekend. The response sets included 17 responses ranged from 0 to $16+\mathrm{h}$. The third item asked respondents how many hours they watched television in total per week with the response set including seven categories $(0-5 \mathrm{~h} ; 6-10 \mathrm{~h}$; 11-15 h; 16-20 h; 21-25 h; 26-30 h, and 31+ h). 


\subsubsection{Perceived Materialism (PMat) in Advertising}

A new measure of this construct was developed for this study because the literature review failed to identify a reliable and valid measure. Participants were instructed to consider the television and consumer magazine ads they recently have seen for consumer goods and services. The exact prompt used was:

There is so much advertising of consumer goods and services around us. We see it all around us on television and consumer magazines. Think about your image of most of the ads you have noticed about consumer goods and services in the last few weeks. Please describe your image of these ads by marking the response that captures your image along the following attributes:

Respondents described their perceptions of materialism of advertising using seven-point semantic-differential scales across a range of attributes: high status/low status; affluent/ non-affluent; high prestige/low prestige; high class/low class; glamorous/non-glamorous; and luxurious/non-luxurious.

\subsubsection{Materialism}

Richins and Dawson (1992) conceptualized and measured materialism using three subdimensions of materialism: centrality, success, and happiness. However, based on a thorough literature review and a discussion of the shortcomings of current materialism measures, the Richins and Dawson's materialism scale was modified to reflect three sources of motivation: (1) the belief in the notion that material possessions leads to happiness in life (Richins and Dawson 1992); (2) the belief that material possessions symbolize achievement and success, which in turn generate social recognition and status (Richins and Dawson 1992), and (3) the belief that material possessions make people feel distinctive from others, which in turn promote self-regard. In other words, it is believed that materialism is best conceptualized in terms of happiness, social recognition, and uniqueness. Therefore, the modified measure of materialism builds on the Richins and Dawson (1992) measure by refining the items related to happiness and social recognition and introducing the new dimension of uniqueness. In addition to introducing a new dimension (i.e., uniqueness), another goal related to modifying the Richins and Dawson's measure is to ensure a better metric invariance across different countries (cf. Wong et al. 2003). Three items were used to measure each of these dimensions on five-point scales $(1=$ strongly agree, $5=$ strongly disagree $)$. The actual items were as follows:

1. Having luxury items is important to a happy life. (happiness dimension)

2. To me, it is important to have expensive homes, cars, clothes, and other things. Having these expensive items makes me happy. (happiness dimension)

3. Material possessions are important because they contribute a lot to my happiness. (happiness dimension)

4. I love to buy new products that reflect status and prestige. (social recognition dimension)

5. I like to own expensive things than most people because this is a sign of success. (social recognition dimension)

6. I feel good when I buy expensive things. People think of me as a success. (social recognition dimension) 
7. I enjoy owning expensive things that make people think of me as unique and different. (uniqueness dimension)

8. I usually buy expensive products and brands to make me feel unique and different. (uniqueness dimension)

9. I usually buy expensive things that make me look distinctive. (uniqueness dimension)

\subsubsection{Frequency of Evaluation of Standard of Living (SOL)}

The measure of frequency of evaluation of SOL was also developed for this study. Respondents were provided with the following prompt: "Most people have strong feelings about their standard of living because they compare their family's current financial situation with different types of standards of comparisons. The questions below are designed to capture the standard of comparison you use in evaluating your family's standard of living." Single items were used to measure each of the six standards of comparison (i.e., ideal, deserved, minimum need, predictive, past, and ability) in evaluating standard of living on 10-point scales where 1 means "no, my feelings about my standard of living are frequently not based on this standard of comparison" and 10 means "yes, my feelings about my standard of living are frequently based on this standard of comparison." The actual items capturing ideal, deserved, and minimum, predictive, past, and ability-based expectations are as follows:

1. Some people compare their family's financial situation with some ideal goal of wealth they desire to have. Thus, they may feel happy with their financial situation because their current situation meets their ideal goal, or they may feel less happy because their current situation is significantly below their ideal. (Ideal-based Expectations of SOL)

2. Some compare their family's financial situation with what they think they deserve to have in life. Thus, they may feel happy with their financial situation because their current situation meets what they think they deserve, or they may feel less happy because their current situation is significantly below what they think they deserve. (Deserved-based Expectations of SOL)

3. Some compare their family's financial situation with what they think they need to have to maintain a certain lifestyle. Thus, they may feel happy with their financial situation because their current situation meets what they think they need, or they may feel less happy because their current situation is significantly below what they think they need. (Minimum-based Expectations of SOL)

4. Some compare their family's financial situation with their past financial situation. Thus, they may feel happy with their financial situation because their current situation is better than their past situation, or they may feel less happy because their current situation is significantly below their past situation. (Past-based Expectations of SOL)

5. Some compare their family's financial situation with what they have predicted all along to have happened to them, financially speaking. Thus, they may feel happy with their financial situation because their current situation is what they have predicted all along or perhaps exceeds their predictive expectations, or they may feel less happy because their current situation is significantly below their prediction of what they should have accomplished. (Predictive-based Expectations of SOL)

6. Some compare their family's financial situation based on their education and skills as well as family status and connections. Thus, they may feel happy with their financial situation because their current situation is better than or equal to what they have expected based on their education, skills, family status, and connections; or they may feel less happy because their current situation is significantly below what they 
expected based on their education, skills, family status, and connections. (Abilitybased Expectations of SOL)

\subsubsection{Satisfaction with SOL}

Two sets of questions were developed to measure satisfaction with SOL. The first set included two rating items. One item asked respondents to rate their current financial situation of their immediate family $(1=$ very poor; $5=$ very healthy). The second item asked participants to report their feelings about their family's current financial situation ( $1=$ very bad; $5=$ very good). The other set included six semantic differential items (Ogden and Venkat 2001). Specifically, participants were asked to report their feelings about the things their family owns, their family's standard of living, and their family's financial situation overall on a seven-point scale (happy/angry; good/bad; elated/tense; contended/frustrated; fulfilled/disappointed; and pleased/displeased).

\subsubsection{Life Satisfaction}

The short version of the Campbell et al. (1976) scale was used to measure life satisfaction. Specifically, participants were asked to rate their life on the following items by using 7-point semantic-differential scales: boring/interesting; useless/worthwhile; full/empty; and discouraging/helpful.

\subsubsection{Item Parceling}

Before conducting the analyses, parceling was used on two sets of measures: materialism and satisfaction with standard of living. Based on Bagozzi and Heatherton's (1994) recommendation, at least two dimensions were created for these constructs to account for measurement error. Because materialism is considered as a three-factor construct (i.e., happiness, social recognition, and uniqueness), the indicators of each factor were summed to develop three dimensions. Satisfaction with standard of living, on the other hand, was represented by two dimensions. One dimension included the rating items while the other dimension included the six semantic-differential items. These item parcels were used in subsequent analyses.

\subsubsection{Testing for Moderation}

Moderation effects were tested by using the unconstrained method described by Marsh et al. (2004). Specifically, the products of centered observed variables were used as indicators of latent interaction terms (i.e., moderators). All possible pairs were used to construct indicators. For variables with item parcels, namely materialism and satisfaction with standard of living, parcels were centered and the products of these centered parcels with other centered variables were used as indicators of moderators.

\section{Results}

The Anderson and Gerbing's (1988) two-step method was applied to estimate the measurement model in the first step and the structural models in the second step. LISREL 8.80 
(Joreskog and Sorbom 2006) was used to analyze the covariance matrices in all analyses. Because the goal of this research was not to look at differences between countries or compare countries in terms of the alternative models, pooled sample was used in all analyses. In other words as a reminder, the goal to collect data from different countries is to generate adequate variance in the constructs, not to conduct cross-cultural comparisons.

\subsection{Measurement Model Results}

Prior to conducting a confirmatory factor analysis (CFA), normality of the observed variables was inspected. Some of the variables had high skewness and kurtosis values. Maximum likelihood (ML) estimation method is considered to be very robust even with highly skewed/kurtosis data. However, it is argued that ML produces too high Chi-square statistic and leads rejecting too many true models when the variables are highly nonnormal (West et al. 1995). To deal with this problem, the Satorra-Bentler corrected Chi-square was used in all analyses.

To estimate the measurement model, the six constructs, namely television viewership, perception of materialism in advertising, materialism, frequency of evaluations of SOL, satisfaction with SOL, and life satisfaction, were modeled as freely correlated first-order factors with their respective indicators. To fix the loadings and measurement errors of item parcels (dimensions) for materialism and satisfaction with standard of living constructs, the Anderson and Gerbing (1988) convention was followed. After computing the composite reliabilities for each dimension, the highest composite reliability for a given construct was chosen. Then, the loading of this dimension on the construct was set equal to the square root of its composite reliability. Finally, the measurement error of this dimension was set to one minus its composite reliability. For instance, materialism had three dimensions (i.e., happiness, social recognition, and uniqueness) and composite reliabilities for each of these dimensions for the pooled sample were $.836, .855$, and .858 , respectively. Because the uniqueness dimension had the highest value, the loading of uniqueness on materialism was set equal to the square root of its composite reliability (i.e., .926), and the measurement error of uniqueness was set to one minus its composite reliability (i.e., .142). The same procedure was followed for satisfaction with SOL.

The Satorra-Bentler scaled Chi-square value for the pooled sample was 856.03 with 239 degrees of freedom. Given the large sample size, the Satorra-Bentler scaled Chi-square value was significant at .001 . However, other goodness-of-fit statistics suggested a close fit to the data with the Root Mean Square Error of Approximation (RMSEA; Steiger and Lind 1980; Browne and Cudeck 1989) $=.048$, Bentler's (1990) Comparative Fit Index $(\mathrm{CFI})=.96$, Standardized Root Mean Square Residual (SRMR; Bentler 1995) $=.048$, and Goodness-of-Fit Index (GFI; Joreskog and Sorbom 1984) $=.93$. Therefore, it was decided that the fit was adequate.

The summary of tests related to the convergent validity (internal consistency) of the constructs and item parcels (dimensions) is shown in Table 2. To demonstrate convergent validity, Average Variance Extracted (AVE) by each construct should be greater than .50 and the composite reliability of a factor should be equal to or greater than .60 (Fornell and Larcker 1981). As Table 2 shows, two of the constructs had AVE less than .50. More specifically, AVE was .488 for exposure to materialistic advertising and AVE was .433 for frequency of evaluations of SOL. Because their composite reliabilities were relatively high (.852 and .820 respectively), their AVE was considered acceptable. All other AVE values ranged from .515 to .683 . Composite reliabilities were greater than .60 with a range of .780 to .864 (excluding parcels). Similarly, coefficient Alphas were relatively high and ranged 
Table 2 Internal consistency results $(\mathrm{N}=1,138)$

\begin{tabular}{llll}
\hline & Coefficient alpha & Composite reliability & AVE \\
\hline TV viewership & .761 & .780 & .540 \\
PMat in advertising & .848 & .852 & .488 \\
Materialism & .914 & .864 & .683 \\
Parcel 1: Happiness & .834 & .836 & .630 \\
Parcel 2: Social recognition & .851 & .855 & .663 \\
Parcel 3: Uniqueness & .850 & .858 & .670 \\
Frequency of evaluations of SOL & .814 & .820 & .433 \\
Satisfaction with SOL & .913 & .795 & .670 \\
Parcel 1: Likert type questions & $.587^{\mathrm{a}}$ & .748 & .600 \\
Parcel 2: Semantic differential & .924 & .957 & .672 \\
Life satisfaction & .794 & .807 & .515 \\
\hline
\end{tabular}

Composite reliability and AVE values for parcels were calculated from separately conducted confirmatory factor analyses; composite reliability and AVE values for latent constructs were calculated from the final confirmatory factor analysis that included all constructs

Coefficient alpha values were calculated by using the original items, not parcels

$A V E$ Average variance explained, SOL Standard of Living

a Pearson correlation for two items $(p<.01)$

from .761 to .914 (excluding parcels). Furthermore, all factor loadings were significant at the .05 level. All these results imply that convergent validity (internal consistency) was satisfactory for the constructs.

To test for discriminant validity, the squares of correlations between any two constructs were compared with the AVE estimates of those two constructs (Fornell and Larcker 1981). The squared correlations ranged from .0004 to .3025 . Because the lowest AVE estimate was .433, the AVE for each construct was greater than its squared correlation with any other construct. Accordingly, it was decided that discriminant validity was supported.

\subsection{Results Pertaining to the Relationship Between Television Viewership and Life Satisfaction}

The first hypothesis is captured in Fig. 1. It was hypothesized that television viewership is not a negative predictor of life satisfaction (H1). As expected, a simple regression reveals that the relationship between television viewership and life satisfaction was negative and low (Beta $=-.06 ; p=.023$ ); however, when the mediating variables were introduced into the analysis this relationship becomes non significant (Standardized Estimate $=-.04$, $p=.242 ;$ Chi-square $=32.64, p<.001 ; \mathrm{RMSEA}=.036 ; \mathrm{CFI}=.99 ; \mathrm{SRMR}=.026$; GFI $=.99$ ). These results provide overall support for the first hypothesis (H1) that the negative relationship between television viewership and life satisfaction is non-significant when controlled for other factors.

\subsection{Materialism and Life Satisfaction}

Several hypotheses dealing with the relationship between materialism and life satisfaction were developed. One hypothesis was stated as follows: Materialism is a negative predictor of life satisfaction (H2). See Fig. 2. As hypothesized, the relationship between materialism 
and life satisfaction was negative and moderately low (Standardized Estimate $=-.15$; $p=.001 ;$ Chi-square $=87.78, p<.001 ;$ RMSEA $=.068 ; \mathrm{CFI}=.98 ;$ SRMR $=.034 ;$ GFI $=.97)$. These results provide support for the second hypothesis (H2).

The bottom-up explanation of the negative relationship between materialism and life satisfaction was tested next (see Model 3a in Fig. 3). It was hypothesized that materialism is a negative predictor of life satisfaction mediated by satisfaction with SOL. Specifically, materialism is a negative predictor of satisfaction with SOL, and satisfaction with SOL is a positive predictor of life satisfaction $(\mathrm{H} 3 \mathrm{a})$. The results show that materialism is not a negative predictor of satisfaction with SOL as hypothesized (Standardized Estimate $=.03$, $p=.43$; R-square $=.000)$, but the positive predictive relationship between satisfaction w/SOL and life satisfaction was confirmed by the data (Standardized Estimate $=.55$, $p<.001$; R-square $=.30$ ). The overall goodness-of fit statistics provided moderate support for the mediation model at large (Chi-square $=179.95, p<.001$; RMSEA $=.071$; $\mathrm{CFI}=.97$; SRMR $=.069$; GFI $=.96)$. These results provide only moderate support for the mediation model (H3a).

Alternatively, it can argued that the predictive effect of satisfaction with SOL on life satisfaction may be moderated by materialism (see Model 3b in Fig. 3). That is, it was hypothesized that materialism moderates the effect of satisfaction with SOL on life satisfaction. Specifically, the strength of the relationship between satisfaction with SOL and life satisfaction is likely to be more evident for materialistic than non-materialistic people (H3b). The results did not support the moderation model (Chi-square $=950.89, p<.001$; RMSEA $=.092 ; \mathrm{CFI}=.93 ; \mathrm{SRMR}=.081$; GFI $=.84$ ).

Next, the concept of frequency of SOL evaluations was injected to further explain the interrelationship between materialism, satisfaction with SOL, and life satisfaction. Thus, two competing models (models $4 \mathrm{a}$ and $4 \mathrm{~b}$ ) shown in Fig. 4 were developed. It was hypothesized that materialism is a negative predictor of life satisfaction mediated by frequency of evaluation of SOL and satisfaction with SOL. Specifically, materialism is a positive predictor of frequency of evaluation of SOL, frequency of evaluation of SOL is a negative predictor of satisfaction with SOL, and satisfaction with SOL is a positive predictor of life satisfaction (H4a). Alternatively, materialism is a positive predictor of frequency of evaluation of SOL, and frequency of evaluation of SOL moderates the relationship between satisfaction with SOL and life satisfaction such that the higher the frequency of evaluation of SOL the stronger the effect of satisfaction with SOL on life satisfaction $(\mathrm{H} 4 \mathrm{~b})$.

With respect to $\mathrm{H} 4 \mathrm{a}$, the overall model and the specific hypothesized links were all supported. Materialism was successful in predicting frequency of evaluation of SOL (Standardized Estimate $=.31, p<.001 ; \mathrm{R}$-square $=.10$ ) ; frequency of evaluation of SOL was successful in predicting satisfaction with SOL (Standardized Estimate $=-.14$, $p<.001$; R-square $=.02$ ), and satisfaction with SOL was successful in predicting life satisfaction (Standardized Estimate $=.55, p<.001$; R-square $=.30$ ). Overall goodnessof-fit statistics were highly supportive of the overall model too (Chi-square $=464.57$, $p<.001 ;$ RMSEA $=.061$ CFI $=.96$; SRMR $=.067$; and GFI $=.94)$.

The alternative model as articulated by H4b (and shown in Fig. 4, Model 4b) was not supported by the data well with Chi-square $=1,997.81, p<.001$; RMSEA $=.068$; $\mathrm{CFI}=.93 ; \mathrm{SRMR}=.086 ;$ and $\mathrm{GFI}=.79$.

\subsection{Television Viewership and Materialism}

Three alternative models were developed to explain the interrelationships between television viewership, perceived materialism (PMat) in advertising, and materialism. 
These models are shown in Fig. 5 (see model 5a, 5b, and 5c). H5a posits that television viewership is a positive predictor of PMat in advertising, which in turn, is a positive predictor of materialism. The results were supportive of the overall model (Chi-square = 269.19, $p<.001$; RMSEA $=.060$; CFI $=.97$; SRMR $=.036$; GFI $=.96$ ). Television viewership failed to predict PMat in advertising (Standardized Estimate $=.02, p=.67$, $\mathrm{R}$-square $=.00)$. However, as expected, PMat in advertising was successful in predicting materialism (Standardized Estimate $=.21, p<.001 ; \mathrm{R}$-square $=.04$ ). Accordingly, it was concluded that this model is partially supported by the data.

$\mathrm{H} 5 \mathrm{~b}$ posits that television viewership is a positive predictor of materialism, moderated by PMat in advertising. Specifically, the predictive effect of television viewership on materialism is stronger for consumers who perceived high (than low) levels of materialism in advertising. The results were not supportive of the overall model (Chi-square $=3159.41$, $p<.001 ; \mathrm{RMSEA}=.078 ; \mathrm{CFI}=.93 ; \mathrm{SRMR}=.081$; GFI $=.69$ ).

The third model (Model 5c in Fig. 5) tested focused on the following hypothesis (H5c): Materialism is a positive predictor of television viewership and exposure to materialistic advertising. Also, television viewership is a positive predictor of PMat in advertising. The data were supportive of the overall model but not all hypothesized links (Chi-square = 268.44, $p<.001$; RMSEA $=.61$; CFI $=.97$; SRMR $=.036$; GFI $=.96$ ). Materialism was not found to be a positive predictor of television viewership (Standardized Estimate $=.02, p=65$; R-square $=.00$ ); television viewership was not successful in predicting PMat in advertising (Standardized Estimate $=.01, p=.74$ ); and PMat in advertising was predicted successfully only by materialism (Standardized Estimate $=.21$, $p<.001$ ). The R-square pertaining to PMat in advertising was .04, accounting for the joint effects of television viewership and materialism.

\section{Discussion}

The results although initially provide support for the predictive negative effect of television viewership on life satisfaction (H1), this relationship diminished to non-significance once the mediating variables were introduced. These findings are highly consistent with the findings of the Morgan and the Rahtz et al. studies (Morgan 1984; Rahtz et al. 1988a, b, 1989) showing significance without controlling for other explanatory variables, and consistent with the Sirgy et al. (1998a)'s finding showing non-significance when explanatory variables are accounted for. These findings are also consistent with the fact that the same data provide much support for the negative relationship between materialism and life satisfaction $(\mathrm{H} 2)$, suggesting that materialism may be a significant explanatory variable.

In light of the study findings, an overall model that is consistent with the data and also theoretically sound is presented. First, let us focus on the relationship between materialism and life satisfaction. The data provide a good measure of support for H3a and H4a. That is, materialism may influence people to engage in frequent evaluations of the standard of living; frequent evaluation of standard of living may cause a heightened sense of dissatisfaction with standard of living, which in turn spills over to life dissatisfaction.

The data also support the notion that perceptions of the extent of materialism in advertising may have a significant influence on materialism-the more people recall materialistic advertising the greater the likelihood that they become materialistic overall. If so, it would be valuable to test an overall model that connects the antecedents and consequences of materialism. Such a model is presented in Fig. 6. 


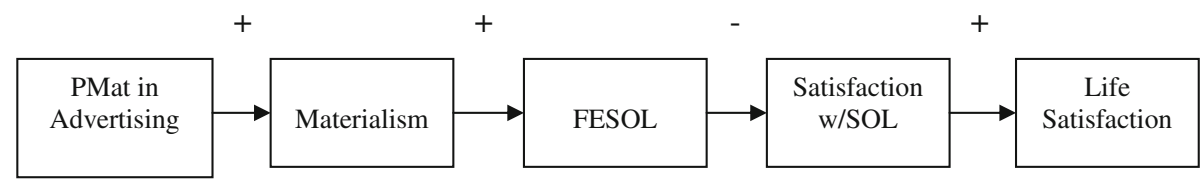

Fig. 6 Testing an integrated model of antecedents and consequences of materialism

The integrated model (as shown in Fig. 6) was formally tested and the results were highly supportive of the model (Chi-square $=782.18, p<.001$; RMSEA $=.053$; CFI $=.96$; SRMR $=.065$; GFI $=.93$ ). PMat in advertising was found to be a successful predictor of materialism (Standardized Estimate $=.22, p<.001 ; \mathrm{R}$-square $=.05)$. Materialism was a good predictor of frequency of evaluation of SOL (Standardized Estimate $=.32, p<.001$; $\mathrm{R}$-square $=.10$ ); frequency of evaluation of SOL also did a reasonable job predicting satisfaction with SOL (Standardized Estimate $=-.14, p<.001$; R-square $=.02$ ); and finally satisfaction with SOL was very successful in predicting life satisfaction (Standardized Estimate $=.55, p<.001 ; \mathrm{R}$-square $=.30$ ).

In sum, the results of this study showed that the extent to which advertising is perceived to be materialistic is indeed a good predictor of materialism. So, in one sense, this study was able to demonstrate that it is perceived materialism in advertising — not simply television viewership - that contributes to materialism (cf. Goldberg and Gorn 1978; Greenberg and Brand 1993; Rahtz et al. 1989). That is, lasting impressions from ads that links consumer goods and services with status and prestige seem to be a key factor influencing the development of materialism (cf. Moschis and Moore 1982; Buijzen and Valkenburg 2003; Prendergast and Wong 2003; Pine and Nash 2002; Richins 1994a, b; Rindfleisch et al. 2008; Tatzel 2002; Wong and Ahuvia 1998).

It was originally hypothesized that television viewership influences materialism through the mediation effect of PMat in advertising. Study results indeed show that materialism is a significant function of PMat in advertising, not television viewership. That is, this study failed to show that television viewership influences PMat in advertising - the greater the television viewership the greater the perceived materialism in advertising. This is clearly in contradiction to much of the research (e.g., O'Guinn and Shrum 1997; Shrum et al. 1998, 2005; Sirgy et al. 1998b) arguing for a direct effect of television viewership on materialism. So how do we account for this discrepancy? The following explanation can be tested through future research. Perhaps, the finding that television viewership is positively related to materialism is a phenomenon that was valid only in the mid-1990s when the data were first collected studying this phenomenon. There are now many more alternative entertainment and media outlets not only in the US but in many countries (both developed and developing). For example, many consumers watch movies through DVDs and paidchannels. When people are asked to report on their television watching behavior, they may count watching DVDs and pre-recoded television shows as television viewership. Watching DVDs has little to do with exposure to materialistic advertising, and watching pre-recoded shows allows television viewers to skip through most of the commercials. Thus, the patterns of television viewership may have changed. Consumers watch fewer, regular television shows with commercial advertising because they pre-record many of their favorite shows and watch them at their time of leisure. Such a trend may have caused a disassociation between television viewership and perceptions of materialism. One can hypothesize that pre-2000 television viewership may be positively related to materialism but post-2000 television viewership may not be related to materialism. Future research may test the hypothesis in formal ways. 
The explanation for the non-significant relationship between television viewership and PMat in advertising may be construed as U.S. ethnocentric, perhaps because the patterns of television viewership in the U.S. may be different from those in other countries such as Egypt, Turkey, and Bosnia and Herzegovina. We looked at this relationship more closely, country by country, and found that the relationship is tenuous at best. Specifically, by using LISREL 8.80, the relationship between TV viewing and PMat Advertising was examined for each individual country as well as for the pooled sample. Based on these results, it was concluded that there is no significant relationship between TV viewing and PMat Advertising. More specifically, the model (i.e., TV viewing $\rightarrow$ PMat Advertising) was not supported by data for four countries (i.e., USA, Australia, Egypt, and Turkey) with high RMSEA and SRMR values and relatively low CFI values. On the other hand, even though the data were supportive of the overall model in three countries (i.e., Bosnia and Herzegovina, Germany, and Korea), the coefficient between TV viewing and PMat Advertising was not significant. Similarly, even though the model was supported by the pooled data, the coefficient between two key variables was not significant.

With respect to the effect of materialism on life satisfaction, this paper sheds more light on how materialism works (cf. Belk 1984; La Barbera and Gurhan 1997; Richins 2004; Richins and Dawson 1992; Sirgy et al. 1998a). This study suggests that materialistic people are likely to engage in frequent evaluations of their SOL, much more so than non-materialistic counterparts. In doing so, materialistic people are more likely to feel dissatisfied with their SOL. This dissatisfaction with an important life domain (i.e., the material life) plays an important role in their overall evaluation of their lives accounting for feelings of life dissatisfaction. This explanation is consistent with a recent study examining the relationship between frequency of social comparisons and subjective well-being (Fujita 2008). This study demonstrated that people experiencing low levels of subjective well-being tend to engage in frequent social comparisons, more so than those experiencing high levels of subjective well-being. Those who engage in frequent comparisons were also found to score highly on measures of neuroticism, a personality trait negatively related with subjective well-being (Diener 1984; Diener et al. 1999).

Do these findings mean that material well-being does not play a significant role in life satisfaction? Materialism is different from material well-being. Materialism refers to the value individuals place on their material life vis-à-vis other life domains such as social life, leisure life, family life, and spiritual life. Material well-being does play a significant role in life satisfaction (Layard 2005). That is, satisfaction with standard of living does contribute to overall happiness in life. Materialism, on the other hand, may adversely affect life satisfaction because materialistic people allocate much of their time, energy, and resources to the pursuit of material gains, which may come at the expense of gains in other important life domains such as social life, family life, leisure life, and spiritual life (Sirgy and Wu 2009).

What are the policy implications of this research? This study has demonstrated a clear connection between advertising and life dissatisfaction. Advertising contributes to materialism by cultivating images that associate the good life with the consumption of status goods and services. In other words, people become more materialistic because they become more exposed to materialistic advertising. When people become more materialistic (treat their material life as more important than other life domains such as work life, social life, family life, community life, and spiritual life), they engage in more frequent evaluations of their SOL, and in doing so, they are likely to feel dissatisfied with their material 
life. These feelings of dissatisfaction contribute significantly to their overall feelings about their life (i.e., they become more dissatisfied with life).

Policy implications may take form in advertising industry policies, policies related to the media industry, and public policies related to the advertising institution. Leaders in the advertising and media industry should encourage advertising professionals, especially those that work in large advertising agencies that develop television commercials targeting general audiences, to tone down the extent to which advertising may be described as materialistic. This means to refrain from creating mental associations between the consumption of consumer goods and services and social status and prestige. Furthermore, television commercials directed to general audiences should not create the impression that the consumption of status goods and services is the most important goal in life. That success in life should not be defined in terms of material possessions. That consumption of status goods and services does not necessarily lead to happiness. Leaders in the media industry, especially executives of television network stations, should be more involved in scrutinizing advertising and encouraging their clients to develop more socially responsible advertisements. Consumer advocacy organizations and government agencies that oversee the advertising industry should also be involved in developing guidelines to advertisers to sensitize them to the subtle and adverse effects of materialistic advertising.

\section{References}

Anderson, J. J., \& Gerbing, D. W. (1988). Structural equation modeling in practice: A review and recommended two-step approach. Psychological Bulletin, 103, 411-423.

Bagozzi, R. P., \& Heatherton, T. F. (1994). A general approach to representing multifaceted personality constructs: Application to state self-esteem. Structural Equation Modeling, 1, 35-67.

Belk, R. W. (1984). Three scales to measure constructs related to materialism: Reliability, validity, and relationships to measures of happiness. In T. Kinnear (Ed.), Advances in consumer research (Vol. 11, pp. 291-297). Ann Arbor: Association for Consumer Research.

Belk, R. W. (1985). Materialism: Trait aspects of living in the material world. Journal of Consumer Research, 12, 265-280.

Belk, R. W., \& Pollay, R. W. (1985a). Images of ourselves: The good life in twentieth century advertising. Journal of Consumer Research, 12, 882-897.

Belk, R. W., \& Pollay, R. P. (1985b). Materialism and magazine advertising during the twentieth century. In E. Hirschman \& M. Holbrook (Eds.), Advances in consumer research (Vol. 12, pp. 394-398). Provo, UT: Association for Consumer Research.

Bentler, P. M. (1990). Comparative fit indexes in structural models. Psychological Bulletin, 107, $238-246$.

Bentler, P. M. (1995). EQS structural equations program manual. Encino: Multivariate Software.

Browne, M. W., \& Cudeck, R. (1989). Single sample cross-validation indices for covariance structures. Multivariate Behavioral Research, 24, 445-455.

Buijzen, M., \& Valkenburg, P. M. (2003). The effects of television advertising on materialism, parent-child conflict, and unhappiness: A review of research. Journal of Applied Developmental Psychology, 24, $437-456$.

Burroughs, J. E., \& Rindfeisch, A. (2002). Materialism and well-being: A conflicting value perspectives. Journal of Consumer Research, 29, 348-370.

Campbell, C. (1987). The romantic ethic and the spirit of modern consumerism. Oxford: Basil Blackwell.

Campbell, A., Converse, P. E., \& Rodgers, W. L. (1976). The quality of America life. New York: Russell Sage Foundation.

Caughey, J. L. (1984). Imaginary social worlds: A cultural approach. Lincoln: University of Nebraska Press.

Chang, L. C., \& Arkin, R. M. (2002). Materialism as an attempt to cope with uncertainty. Psychology and Marketing, 19, 389-406.

Churchill, G. A., Jr., \& Moschis, G. P. (1979). Television and interpersonal influences on adolescent consumer learning. Journal of Consumer Research, 6, 23-35. 
Dawson, S., \& Bamossy, G. (1991). If we are what we have, what are we when we don't have? An exploratory study of materialism among expatriate-Americans. Journal of Social Behavior and Personality, 6, 363-384.

Diener, E. (1984). Subjective well-being. Psychological Bulletin, 95, 542-575.

Diener, E., Suh, E. M., Lucas, R. E., \& Smith, H. L. (1999). Subjective well-being: three decades of research. Psychological Bulletin, 125, 276-302.

Fornell, C., \& Larcker, D. F. (1981). Evaluating structural equation models with unobservable variables and measurement errors. Journal of Marketing Research, 18, 39-50.

Fox, W. S., \& Philliber, W. W. (1978). Television viewing and the perception of affluence. Sociological Quarterly, 19, 103-112.

Frisch, M. B. (2006). Quality of life therapy: Applying a life satisfaction approach to positive psychology and cognitive therapy. Hoboken: Wiley.

Frisch, M. B. (2008). Quality of life coaching and therapy (QOLC/T): A new system of positive psychology and subjective well-being interventions. In M. Eid \& R. J. Larsen (Eds.), The science of subjective well-being. New York: Guilford Press.

Fujita, F. (2008). The frequency of social comparison and its relation to subjective well-being. In M. Eid \& R. J. Larsen (Eds.), The science of subjective well-being (pp. 239-257). New York: Guilford Press.

Gerbner, G., Gross, L., Morgan, M., \& Sigroniel, N. (1980a). Aging and television images on television drama and conceptions of social reality. Journal of Communication, 30, 37-47.

Gerbner, G., Gross, L., Morgan, M., \& Sigroniel, N. (1980b). The main streaming of America: Violence profile no. 11. Journal of Communication, 30, 10-29.

Goldberg, M. E., \& Gorn, G. J. (1978). Some unintended consequences of tv advertising to children. Journal of Consumer Research, 5, 22-29.

Greenberg, B. S., \& Brand, J. E. (1993). Television news and advertising in schools: The "Channel One" controversy. Journal of Communication, 43, 143-151.

Hawkins, R. P., \& Pingree, S. (1981). Using television to construct social reality. Journal of Broadcasting, $25,347-364$.

Hyman, M. R., Tansey, R., \& Clark, J. W. (1994). Research on advertising ethics: Past, present, and future. Journal of Advertising, 23, 5-14.

Joreskog, K., \& Sorbom, D. (1984). Lisrel VI user's guide. Mooresville: Scientific Software International.

Joreskog, K., \& Sorbom, D. (2006). Lisrel 8.80 user's guide. Lincolnwood: Scientific Software International.

Keng, K. A., Jung, K., Jiuan, T. S., \& Wirtz, J. (2000). The influence of materialistic inclination on values, life satisfaction, and aspirations: An empirical analysis. Social Indicators Research, 49, 317-333.

La Barbera, P. A., \& Gurhan, Z. (1997). The role of materialism, religiosity, and demographics in subjective well-being. Psychology and Marketing, 14, 71-97.

Larsen, V., Sirgy, J. M., \& Wright, N. D. (1999). Materialism: the construct, measures, antecedents, and consequences. Academy of Marketing Studies Journal, 3, 75-107.

Layard, R. (2005). Happiness: Lessons from a new science. New York: The Penguin Press.

Lee, W. (1989). The mass-mediated consumption realities of three cultural groups. In T. Srull (Ed.), Advances in consumer research (Vol. 16, pp. 779-785). Provo: Association for Consumer Research.

Marsh, H. W., Wen, Z., \& Hau, K. T. (2004). Structural equation models of latent interactions: Evaluation of alternative estimation strategies and indicator construction. Psychological Methods, 9, 275-300.

Morgan, M. (1984). Heavy television viewing and perceived quality of life. Journalism Quarterly, 61, 499-504.

Moschis, G. P., \& Moore, R. L. (1982). A longitudinal study of television advertising effects. Journal of Consumer Research, 9, 279-286.

O'Guinn, T. C., Faber, R. J., Curias, N. J. J., \& Schmitt, K. (1989). The cultivation of consumer norms. In T. Srull (Ed.), Advances in Consumer Research (Vol. 16, pp. 779-785). Provo: Association for Consumer Research.

O'Guinn, T. C., Lee, W. A., \& Faber, R. J. (1986). Acculturation: The impact of divergent paths on buyer behavior. In R. J. Lutz (Ed.), Advances in consumer research (Vol. 13, pp. 579-583). Provo: Association for Consumer Research.

O'Guinn, T. C., \& Shrum, L. J. (1997). The role of television in the construct of social reality. Journal of Consumer Research, 23, 278-294.

O'Shaughnessy, J., \& O'Shaughnessy, N. J. (2002). Marketing, the consumer society and hedonism. European Journal of Marketing, 36, 524-547.

Ogden, H. J., \& Venkat, R. (2001). Social comparison and possessions: Japan vs. Canada. Asia Pacific Journal of Marketing and Logistics, 13, 72-84. 
Pine, K. J., \& Nash, A. (2002). Dear Santa: The effects of television advertising on young children. International Journal of Behavioral Development, 26, 529-539.

Pollay, R. W. (1986). The distorted mirror: Reflections on the unintended consequences of advertising. Journal of Marketing, 50, 18-30.

Potter, W. J. (1991). Examining cultivation from a psychological perspective. Communications Research, $18,92-113$.

Prendergast, G., \& Wong, C. (2003). Parental influence on the purchase of luxury brands of infant apparel: an exploratory study in Hong Kong. Journal of Consumer Marketing, 20, 157-169.

Rahtz, D. R., Sirgy, M. J., \& Meadow, H. L. (1988a). Elderly life satisfaction and television viewership: An exploratory study. In M. Houston (Ed.), Advances in consumer research (Vol. 15, pp. 141-145). Ann Arbor: Association for Consumer Research.

Rahtz, D. R., Sirgy, M. J., \& Meadow, H. L. (1988b). Elderly life satisfaction and television viewership: Replication and extension. In S. Shapiro (Ed.), AMA winter educators' conference in marketing: A return to the broader dimensions (pp. 409-413). Chicago: American Marketing Association.

Rahtz, D. R., Sirgy, M. J., \& Meadow, H. L. (1989). The elderly audience: Correlates of television orientation. Journal of Advertising, 18, 9-20.

Richins, M. L. (1987). Media, materialism, and human happiness. In M. Wallendorf \& P. Anderson (Eds.), Advances in consumer research (Vol. 14, pp. 352-356). Ann Arbor: Association for Consumer Research.

Richins, M. L. (1994a). Special possessions and the expression of material values. Journal of Consumer Research, 21, 522-531.

Richins, M. L. (1994b). Valuing things: The public and private meanings of possessions. Journal of Consumer Research, 2, 504-521.

Richins, M. L. (2004). The material values scale: Measurement properties and development of a short form. Journal of Consumer Research, 31, 209-219.

Richins, M. L., \& Dawson, S. (1992). A consumer values orientation for materialism and its measurement: Scale development and validation. Journal of Consumer Research, 19, 303-316.

Rindfleisch, A., Burroughs, J. E., \& Wong, N. (2008). The safety of objects: Materialism, existential insecurity, and brand connections. Journal of Consumer Research, 36, 1-16.

Schudson, M. (1984). Advertising, the uneasy persuasion. Ney York: Basic Books.

Shrum, L. J. (1999). Television and persuasion: Effects of the programs between the ads. Psychology and Marketing, 16, 119-140.

Shrum, L. J., Burroughs, J. E., \& Rindfleisch, A. (2005). Television's cultivation of material values. Journal of Consumer Research, 32, 473-479.

Shrum, L. J., O’Guinn, T. C., Semenik, R. J., \& Faber, R. J. (1991). Processes and effects in the construction of normative consumer beliefs: The role of television. In R. H. Holman \& M. R. Solomon (Eds.), Advances in consumer research (Vol. 18, pp. 755-763). Provo: Association for Consumer Research.

Shrum, L. J., Wyer, R. S., \& O'Guinn, T. C. (1998). The effects of television consumption on social perceptions: The use of priming procedures to investigate psychological processes. Journal of Consumer Research, 24, 447-458.

Sirgy, M. J. (1998). Materialism and quality of life. Social Indicators Research, 43, 227-260.

Sirgy, M. J., Lee, D. J., Kosenko, R., Meadow, H. L., Rahtz, D., Cicic, M., et al. (1998a). Does television viewership play a role in the perception of quality of life? Journal of Advertising, 27, 125-142.

Sirgy, M. J., Lee, D. J., Larsen, V., \& Wright, N. D. (1998b). Satisfaction with material possessions and general well-being: the role of materialism. Journal of Consumer Satisfaction/Dissatisfaction and Complaint Behavior, 11, 103-118.

Sirgy, M. J., \& Wu, J. (2009). The pleasant life, the engaged life, and the meaningful life: What about the balanced life? Journal of Happiness Studies, 10, 183-196.

Steiger, J. H., \& Lind, J. L. (1980). May). Iowa City: Statistically based tests for the number of factors. Paper presented at the annual spring meeting of the Psychometric Society. IA.

Tatzel, M. (2002). Money worlds and well-being: An integration of money dispositions, materialism, and price-related behaviors. Journal of Economic Psychology, 23, 103-126.

Weiman, G. (1984). The images of life in America. International Journal of Intercultural Relations, 8, 185-197.

West, S. G., Finch, J. F., \& Curran, P. J. (1995). Structural equation models with nonnormal variables: Problems and remedies. In R. H. Hoyle (Ed.), Structural equation modeling: Concepts, issues, and applications (pp. 56-75). Thousand Oaks: Sage.

Wong, N. Y., \& Ahuvia, A. (1998). Personal taste and family face: Self-concepts and luxury consumption in Confucian and Western societies. Psychology and Marketing, 15, 423-441. 
Wong, N., Rindflisch, A., \& Burroughs, J. E. (2003). Do reverse-worded items confound measures in crosscultural consumer research? The case of the material values scale. Journal of Consumer Research, 30, 72-91.

Wright, N. D., \& Larsen, V. (1993). Materialism and life satisfaction: A meta-analysis. Journal of Consumer Satisfaction, Dissatisfaction and Complaining Behavior, 6, 158-165.

Zinkhan, G. (1994). Advertising, materialism, and quality of life. Journal of Advertising, 23, 1-4.

Zinkhan, G., \& Prenshaw, P. J. (1994). Good life images and brand name associations: Evidence from Asia, America, and Europe. In C. Allen \& D. R. John (Eds.), Advances in consumer research (Vol. 21). Provo: Association for Consumer Research. 